\title{
Recent progress in atomic layer deposition of molybdenum disulfide: a mini review
}

\author{
Yazhou Huang ${ }^{1,2}$ and Lei Liu $^{2 *}$
}

\begin{abstract}
As a kind of specially modified chemical vapor deposition (CVD), atomic layer deposition (ALD) has long been used to fabricate thin films. The self-limiting reaction of ALD endows the films with excellent uniformity and precise controllability. The thickness of the films obtained by ALD can be controlled in an atomic scale $(0.1 \mathrm{~nm})$ on a large-area substrate even with complex structures. Therefore, it has recently been employed to produce the two-dimensional (2D) materials like $\mathrm{MoS}_{2}$. In this mini-review, the research progress in $\mathrm{ALD} \mathrm{MoS}$ is firstly summarized. Then the influences of precursors, substrates, temperature, and post-annealing treatment on the quality of $\mathrm{ALD}-\mathrm{MoS}_{2}$ are presented. Moreover, the applications of the obtained $\mathrm{MoS}_{2}$ as an electrochemical catalysator are also described. Besides the perspective on the research of ALD of $\mathrm{MoS}_{2}$, the remaining challenges and promising potentials are also pointed out.
\end{abstract}

Keywords: $\mathrm{MoS}_{2}$, chemical vapor deposition (CVD), atomic layer deposition (ALD), two-dimensional (2D) materials

\section{INTRODUCTION}

Recently, as one of the dimensional (2-D) materials, $\mathrm{MoS}_{2}$ has attracted wide attention owing to its excellent semiconducting and optical properties [1-5]. For layered $\mathrm{MoS}_{2}$, the structure of hexagonal networks connected by covalent bonds of Mo and S atoms is very stable, and the weak interlayer-binding relies on the van der Waals force [6,7], which endows $\mathrm{MoS}_{2}$ with the band-gap structure depending on the layer number strongly. When the bulk $\mathrm{MoS}_{2}$ is exfoliated into monolayer, its band-gap will increase from $\sim 1.2 \mathrm{eV}$ (indirect) to $\sim 1.8 \mathrm{eV}$ (direct) [8,9]. Meanwhile, the current on/off ratio $\left(1 \times 10^{8}\right)$ and the carrier mobility $\left(15 \mathrm{~cm}^{2} \mathrm{~V}^{-1} \mathrm{~s}^{-1}\right)$ at room temperature give $\mathrm{MoS}_{2}$ huge possibilities in electronics and optoelectronics $[6,10,11]$.

Continuous efforts are made for achieving monolayer or ultrathin $\mathrm{MoS}_{2}$ films. Although mechanical exfoliation from bulk $\mathrm{MoS}_{2}$ crystals is a common method to obtain monolayer $\mathrm{MoS}_{2}$, the efficiency is too low to feed the demands of large-scale fabrications [12,13]. The chemical vapor deposition (CVD) has been a useful way to producing thin $\mathrm{MoS}_{2}$ films by sulfurizing $\mathrm{MoO}_{2}$ films between 850 and $950^{\circ} \mathrm{C}$ [14] or Mo films at $750^{\circ} \mathrm{C}$ [15], $900^{\circ} \mathrm{C}$ [16] and $1,050^{\circ} \mathrm{C}$ [17], directly depositing on $\mathrm{Au}$ [18], modified $\mathrm{SiO}_{2}$ [19] or bare $\mathrm{SiO}_{2}$ [20-22] between 530 and $800^{\circ} \mathrm{C}$ using Mo- and S-precursors, which indicates that the precursors, substrates and temperature influence the qualities of the obtained films. A flat substrate ensures the growth of a high quality $\mathrm{MoS}_{2}$ film with a smooth surface and small lattice mismatch rather than nanostructures with large aspect ratios. However, the CVD method is unsuitable for mass fabrication owing to the poor reproducibility and reliability. As a kind of specially modified CVD, atomic layer deposition (ALD) is also used to grow thin films by the self-limiting chemical reaction. The chemical reaction in time sequence can be broken by dividing a complete reaction into two halfreactions in one ALD cycle. One half-reaction cannot stop until the active sites at the surface are depleted, then beginning the other half-reaction [23-27]. During the ALD, the chemical reaction on a new atomic layer is directly related to the previous layer, which makes every reaction only deposit one atomic layer. Due to the selflimiting reaction, not only the thickness of the films can be controlled at an atomic scale, but also the uniformity can be kept on a large-area substrate even with complex structures [28]. Moreover, ALD has a high reproducibility because the growth is insensitive to excessive precursors. Therefore, ALD has been an excellent method to fabricate 2-D $\mathrm{MoS}_{2}$ films.

According to Fig. 1, where recent research progress in the preparation of $\mathrm{MoS}_{2}$ by CVD [14-19,21-22] and ALD

\footnotetext{
${ }^{1}$ Industrial Center, Nanjing Institute of Technology, Nanjing 211167, China

${ }^{2}$ Jiangsu Key Laboratory for Design and Manufacture of Micro-Nano Biomedical Instruments, Southeast University, Nanjing 211189, China

* Corresponding author (email: liulei@seu.edu.cn)
} 


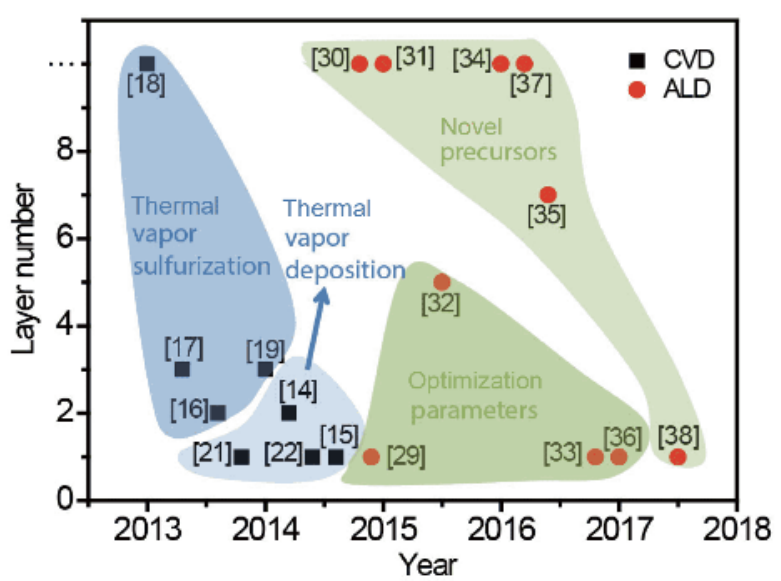

Figure 1 Research progress in the preparation of $\mathrm{MoS}_{2}$ by CVD and ALD.

[29-38] is shown, CVD contains two different means. One is the thermal vapor sulfurization where the $\mathrm{MoS}_{2}$ film is obtained by sulfurizing the pre-deposited molybdenum film at high temperature. The other is thermal vapor deposition where Mo- and S-precursors enter the reactor at the same time to deposit the $\mathrm{MoS}_{2}$ film. Like CVD, ALD also contains two different means. One is the optimization of process parameters while $\mathrm{MoCl}_{5}$ and $\mathrm{H}_{2} \mathrm{~S}$ are used as the precursors. The other is to find the novel precursors. Although ALD of $\mathrm{MoS}_{2}$ appears later, it will able to grow monolayer $\mathrm{MoS}_{2}$ as same as the CVD.

Our group has been able to obtain monolayer $\mathrm{MoS}_{2}$ directly by ALD, and the thickness of $\mathrm{MoS}_{2}$ can be locally controlled layer by layer $[36,39,40]$. In this review, both the research progress in ALD of $\mathrm{MoS}_{2}$ and the application prospect of the obtained $\mathrm{MoS}_{2}$ as an electrochemical catalysator are shown. According to the discussion about the influences of the precursor, substrate, temperature, and post-annealing treatment on the quality of ALD$\mathrm{MoS}_{2}$, the challenges and potentials to obtain high-quality $\mathrm{MoS}_{2}$ by ALD are also pointed out.

\section{ALD OF $\mathrm{MoS}_{2}$ FILMs}

Tan et al. [29] firstly prepared $\mathrm{MoS}_{2}$ by ALD on a sapphire substrate while $\mathrm{MoCl}_{5}$ and $\mathrm{H}_{2} \mathrm{~S}$ were used as Mo- and S-precursors at $300^{\circ} \mathrm{C}$. As shown in Fig. 2, one ALD cycle contains four steps: pulse and purge $\mathrm{MoCl}_{5}$, pulse and purge $\mathrm{H}_{2} \mathrm{~S}$. In the growth process, the corresponding chemical adsorption and reaction can be [39] (A) $\mathrm{Mo}-\mathrm{SH}^{*}+\mathrm{MoCl}_{5} \rightarrow \mathrm{Mo}-\mathrm{S}-\mathrm{MoCl}_{4}{ }^{*}+\mathrm{HCl}$; (B) $\mathrm{MoCl}^{*}+\mathrm{H}_{2} \mathrm{~S} \rightarrow \mathrm{Mo}-\mathrm{SH}^{*}+\mathrm{HCl}+\mathrm{S}$, where $*$ denotes the surface species.

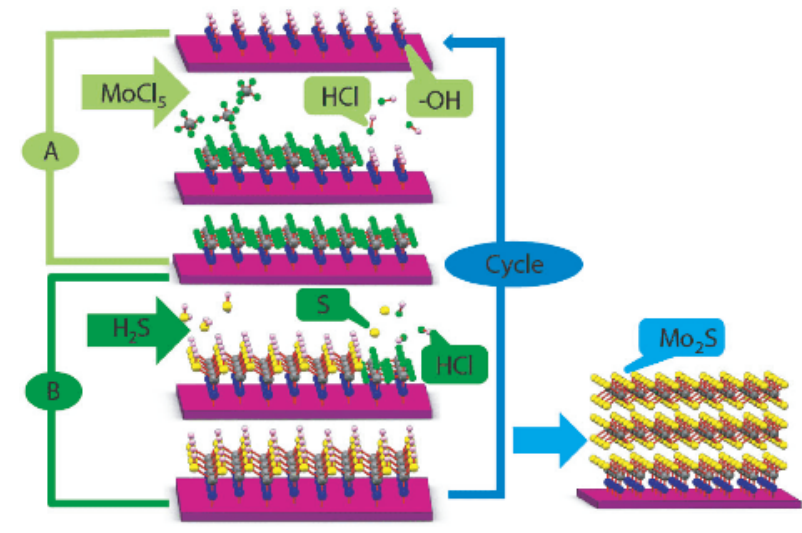

Figure 2 Schematic showing of the ALD of $\mathrm{MoS}_{2}$.

$\mathrm{MoCl}_{5}$ can be adsorbed to the substrate (A) or reacted with $\mathrm{H}_{2} \mathrm{~S}$ (B) by the self-limiting reaction. The $\mathrm{MoS}_{2}$ films with a controllable thickness and uniform coverage can be fabricated by controlling the $\mathrm{AB}$ sequence. At the beginning, $\mathrm{MoCl}_{5}$ is adsorbed to the bare substrate by the hydroxyl group, $\left|-\mathrm{OH}^{*}+\mathrm{MoCl}_{5} \rightarrow\right|-\mathrm{O}-\mathrm{MoCl}_{4}{ }^{*}+\mathrm{HCl}$, where $\mid-$ denotes the surface.

Therefore, the chemical functional group like hydroxyl on the substrate surface should be noticed in the initial growth, especially for mono- or few-layer $\mathrm{MoS}_{2}$. In addition, there are two questions also need to be paid attention. On the one hand, the by-product contains $\mathrm{HCl}$ and S, which can corrode and damage the ALD reactor. On the other hand, because ALD is carried out at relatively low temperature, the as-grown $\mathrm{MoS}_{2}$ always presents a low crystallinity and the post-annealing is usually necessary to achieve a high crystal quality. Accordingly, the precursor, substrate, temperature and post-annealing treatment have important influences on the quality of the $\mathrm{MoS}_{2}$ film obtained by ALD. Therefore, these factors will be focused on in the next part.

\section{Precursors and qualities of $\mathrm{MoS}_{2}$ films obtained by ALD}

Mo- and S-precursors may strongly affect the quality of $\mathrm{MoS}_{2}$ obtained by ALD. However, it is a big challenge that finding or synthesizing suitable precursors for ALD of $\mathrm{MoS}_{2}$. Furthermore, it is difficult to obtain a Moprecursor that can rapidly react with $\mathrm{H}_{2} \mathrm{~S}$, which is a frequently-used S-precursor in ALD of $\mathrm{MoS}_{2}$. The reactivity and the volatility of the precursors ensure the self-limiting surface reaction. This depends on not only the fundamental chemical science but also the industrial engineering. The progress of the ALD technology is determined by the development of high quality precursors. Since $\mathrm{MoCl}_{5}$ and $\mathrm{H}_{2} \mathrm{~S}$ as precursors opened the 

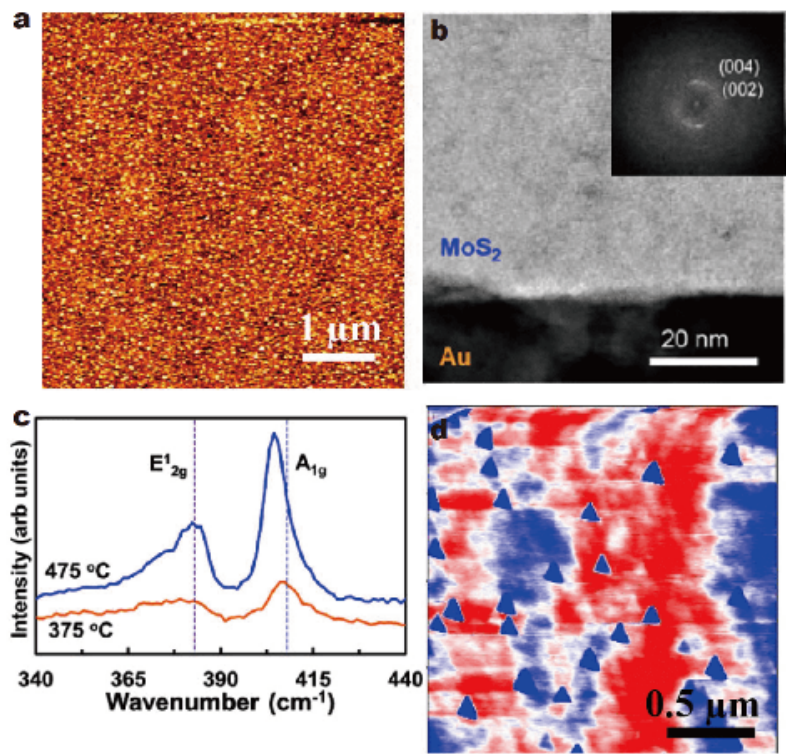

Figure 3 (a) AFM image for the $\mathrm{MoS}_{2}$ film grown on sapphire at $300^{\circ} \mathrm{C}$ using $\mathrm{MoCl}_{5}$ and $\mathrm{H}_{2} \mathrm{~S}$. Reprinted with permission from Ref. [29], Copyright 2014, Royal Society of Chemistry. (b) TEM images for the $\mathrm{MoS}_{2}$ film grown on $\mathrm{Au}$ at $250^{\circ} \mathrm{C}$ using $\mathrm{MoCl}_{5}$ and $\mathrm{H}_{2} \mathrm{~S}$. Reprinted with permission from Ref. [41], Copyright 2017, American Chemical Society. (c) Raman spectra comparing $\mathrm{MoS}_{2}$ films obtained by ALD at 375 and $475^{\circ} \mathrm{C}$. Reprinted with permission from Ref. [33], Copyright 2016, American Vacuum Society. (d) AFM image for the $\mathrm{MoS}_{2}$ film grown on $\mathrm{SiO}_{2}$ at $450^{\circ} \mathrm{C}$ using $\mathrm{MoCl}_{5}$ and $\mathrm{H}_{2} \mathrm{~S}$. Reprinted with permission from Ref. [36], Copyright 2017, IOP Publishing Ltd.

prelude of ALD of $\mathrm{MoS}_{2}$ in 2014 [29], how to produce the high quality $\mathrm{MoS}_{2}$ film by ALD has become a hot spot. On the one hand, the two precursors, $\mathrm{MoCl}_{5}$ and $\mathrm{H}_{2} \mathrm{~S}$ are still used, and the film quality is improved by optimizing the process parameters $[33,36,39-41]$. On the other hand, the new precursors are tested $[30,31,37,38,42-47]$.

For the first time, $\mathrm{MoCl}_{5}$ and $\mathrm{H}_{2} \mathrm{~S}$ were used to grow the $\mathrm{MoS}_{2}$ film on a sapphire substrate at $300^{\circ} \mathrm{C}$. The atomic force microscopy (AFM) image of the as-grown $\mathrm{MoS}_{2}$ film [29] is shown in Fig. 3a, where the grain with an obscure shape indicates the $\mathrm{MoS}_{2}$ film is amorphous and the thickness per ALD cycle (GPC) is $0.21 \mathrm{~nm} /$ cycle. When the substrate is Au (Fig. 3b), the as-grown $\mathrm{MoS}_{2}$ film is still amorphous [41] due to the low growth temperature. Subsequently, while the temperature rose to $475^{\circ} \mathrm{C}$ [33], the uniform $\mathrm{MoS}_{2}$ film grown on a quartz substrate with the diameter of $150 \mathrm{~mm}$ can be obtained. According to Raman spectra (Fig. 3c), the crystallinity of the $\mathrm{MoS}_{2}$ film grown at $475^{\circ} \mathrm{C}$ was obviously improved compared with that obtained at $375^{\circ} \mathrm{C}$. Moreover, by the continuous optimization of process parameters, the $\mathrm{MoS}_{2}$ film with triangle grains (Fig. 3d) was directly obtained at $450^{\circ} \mathrm{C}$ on a $\mathrm{SiO}_{2}$ substrate without the post-annealing [36]. However, the grain size of $\sim 100 \mathrm{~nm}$ is much smaller than that obtained by CVD. Continuous efforts have been made to find the new precursors with which the high quality $\mathrm{MoS}_{2}$ film is directly obtained by ALD.

$\mathrm{Mo}\left(\mathrm{NMe}_{2}\right)_{4}$ with a high activity was used to react with $\mathrm{H}_{2} \mathrm{~S}$ for $\mathrm{ALD}$ of $\mathrm{MoS}_{2}$ on the amorphous $\mathrm{Al}_{2} \mathrm{O}_{3}$ substrate at $150^{\circ} \mathrm{C}$ [38]. Owing to the high reactivity of $\mathrm{Mo}\left(\mathrm{NMe}_{2}\right)_{4}$, the reaction can be carried out at a very low temperature $\left(80^{\circ} \mathrm{C}\right)$. The grown $\mathrm{MoS}_{2}$ films can be directly patterned by the photolithography for the micro-nano devices on a large scale. However, the crystallinity of the obtained $\mathrm{MoS}_{2}$ film is very poor due to the low temperature. $\mathrm{CH}_{3} \mathrm{~S}_{2} \mathrm{CH}_{3}$ was also used to react with $\mathrm{Mo}\left(\mathrm{NMe}_{2}\right)_{4}$ [45]. The obtained $\mathrm{MoS}_{2}$ film with a poor crystallinity is also owing to the low growth temperature. While $\mathrm{Mo}(\mathrm{CO})_{6}$ and $\mathrm{CH}_{3} \mathrm{~S}_{2} \mathrm{CH}_{3}$ were chosen as Mo- and S-precursors, the $\mathrm{MoS}_{2}$ film can directly grow on a $\mathrm{SiO}_{2} / \mathrm{Si}$ substrate at $100^{\circ} \mathrm{C}$ [30]. Thicknesses of the films against the exposure time of $\mathrm{Mo}(\mathrm{CO})_{6}$ and $\mathrm{CH}_{3} \mathrm{~S}_{2} \mathrm{CH}_{3}$ were used to confirm the self-limiting reactions of the precursors. The grown $\mathrm{MoS}_{2}$ film still has a low crystallinity owing to the low growth temperature. $\mathrm{H}_{2} \mathrm{~S}$ was also used to react with $\mathrm{Mo}(\mathrm{CO})_{6}$ on a wafer-scale $\mathrm{SiO}_{2} / \mathrm{Si}$ substrate at $165^{\circ} \mathrm{C}$ [35]. The grown $\mathrm{MoS}_{2}$ film with a precise controllability and favorable uniformity is also amorphous. Moreover, the $\mathrm{H}_{2} \mathrm{~S}$ plasma with a higher reactivity was used to react with $\mathrm{Mo}(\mathrm{CO})_{6}$ on $\mathrm{SiO}_{2}$ at $175^{\circ} \mathrm{C}$ [37]. The $\mathrm{MoS}_{2}$ film could also grow on a wafer-scale $\mathrm{SiO}_{2}$ while $\mathrm{Mo}$ (thd $)_{3}$ and $\mathrm{H}_{2} \mathrm{~S}$ were used as precursors at $300^{\circ} \mathrm{C}$ [46]. Although, this is the highest growth temperature when the organometallic compounds are used as Mo-precursors, the films just have nano-crystalline structures.

Some precursors for ALD of $\mathrm{MoS}_{2}$ that have been reported in literatures are listed in Table 1 . The grain size and GPC of the grown $\mathrm{MoS}_{2}$ film are variable with the precursor, substrate, and growth temperature. While $\mathrm{MoCl}_{5}$ and $\mathrm{H}_{2} \mathrm{~S}$ are used as Mo- and S-precursors, the grain size increases from $\sim 6.1$ to $\sim 120 \mathrm{~nm}$ as the growth temperature rises from 250 to $450^{\circ} \mathrm{C}$, which indicates the higher temperature is propitious to ALD of $\mathrm{MoS}_{2}$. Meanwhile, as novel Mo-precursors, metal-organic compounds such as $\mathrm{Mo}(\mathrm{CO})_{6}, \quad \mathrm{Mo}(\text { thd })_{3}$ and $\mathrm{Mo}\left(\mathrm{NMe}_{2}\right)_{4}$ exhibit higher reactivities than $\mathrm{MoCl}_{5}$ at low temperature. The grown films have the favorable conformity and uniformity, but their crystallinity and GPC are low. As described above, metal-organic and metal-halide compounds are used as Mo-precursors for ALD of $\mathrm{MoS}_{2}$, where the metal-organic presents a higher reactivity, lower crystallinity and GPC. Moreover, 
Table 1 Various Mo- and S- precursors for ALD of $\mathrm{MoS}_{2}$

\begin{tabular}{|c|c|c|c|c|c|c|}
\hline Mo-precursor & S-precursor & Temp. $\left({ }^{\circ} \mathrm{C}\right)$ & Substrate & GPC (nm/cycle) & Grain size & Ref. \\
\hline $\mathrm{MoCl}_{5}$ & $\mathrm{H}_{2} \mathrm{~S}$ & 300 & Sapphire & 0.21 & Amorphous & [29] \\
\hline $\mathrm{MoCl}_{5}$ & $\mathrm{H}_{2} \mathrm{~S}$ & 250 & $\mathrm{Au}$ & I & $6.1 \mathrm{~nm}$ & {$[41]$} \\
\hline $\mathrm{MoCl}_{5}$ & $\mathrm{H}_{2} \mathrm{~S}$ & 375 & $\mathrm{SiO}_{2}$ & 0.025 & Amorphous & [33] \\
\hline $\mathrm{MoCl}_{5}$ & $\mathrm{H}_{2} \mathrm{~S}$ & $430-470$ & $\mathrm{Si}, \mathrm{SiO}_{2}$ & 0.38 & $35-120 \mathrm{~nm}$ & {$[39,40]$} \\
\hline $\mathrm{MoCl}_{5}$ & $\mathrm{H}_{2} \mathrm{~S}$ & 450 & $\mathrm{SiO}_{2}$ & 0.65 & $100 \mathrm{~nm}$ & {$[36]$} \\
\hline $\mathrm{Mo}(\mathrm{CO})_{6}$ & $\mathrm{CH}_{3} \mathrm{~S}_{2} \mathrm{CH}_{3}$ & $100-120$ & $\mathrm{SiO}_{2}$ & 0.11 & Amorphous & {$[30]$} \\
\hline $\mathrm{Mo}(\mathrm{CO})_{6}$ & $\mathrm{H}_{2} \mathrm{~S}$ & $155-175$ & $\mathrm{Co}, \mathrm{SiO}_{2}$ & 0.074 & Amorphous & {$[43,35]$} \\
\hline $\mathrm{Mo}(\mathrm{CO})_{6}$ & $\mathrm{H}_{2} \mathrm{~S}$ plasma & $175-200$ & $\mathrm{SiO}_{2}$ & 0.05 & $20 \mathrm{~nm}$ & [37] \\
\hline $\mathrm{Mo}\left(\mathrm{NMe}_{2}\right)_{4}$ & $\mathrm{H}_{2} \mathrm{~S}$ & $60-120$ & $\mathrm{Al}_{2} \mathrm{O}_{3}$ & I & Amorphous & [38] \\
\hline $\mathrm{Mo}(\mathrm{CO})_{6}$ & $\mathrm{H}_{2} \mathrm{~S}$ plasma & 200 & $\mathrm{Si}$ & I & $5-20 \mathrm{~nm}$ & {$[42]$} \\
\hline $\operatorname{Mo}(\text { thd })_{3}$ & $\mathrm{H}_{2} \mathrm{~S}$ & 300 & $\mathrm{Si}$, etc. & 0.025 & $10-30 \mathrm{~nm}$ & {$[46]$} \\
\hline $\mathrm{Mo}\left(\mathrm{NMe}_{2}\right)_{4}$ & $\mathrm{CH}_{3} \mathrm{~S}_{2} \mathrm{CH}_{3}$ & 50 & $\mathrm{SiO}_{2}$ & I & Amorphous & {$[45]$} \\
\hline $\mathrm{MoF}_{6}$ & $\mathrm{H}_{2} \mathrm{~S}$ & 200 & $\mathrm{Si}$ & 0.06 & Amorphous & [47] \\
\hline
\end{tabular}

although the grain size can be increased by elevating the growth temperature, it is still much smaller than that obtained by CVD. Therefore, the precursors that can be directly and safely used to fabricate the $\mathrm{MoS}_{2}$ film with high quality are still in need.

\section{ALD temperature windows of $\mathrm{MoS}_{2}$}

ALD is carried out within a temperature range, the ALD window related to the precursors [48]. As shown in Fig. 4a, the ALD window of $\mathrm{MoCl}_{5}$ and $\mathrm{H}_{2} \mathrm{~S}$ is kept in $440-470^{\circ} \mathrm{C}$ [39]. If the temperature is lower than $440^{\circ} \mathrm{C}$, the surface reactions will be incomplete. The chemical reactivity and occupation of $\mathrm{MoCl}_{5}$ and $\mathrm{H}_{2} \mathrm{~S}$ can be improved by elevating the temperature. However, if the temperature is higher than $470^{\circ} \mathrm{C}$, the re-evaporation of the grown $\mathrm{MoS}_{2}$ film leads to the decrease of GPC. While $\mathrm{Mo}(\mathrm{CO})_{6}$ is used to replace $\mathrm{MoCl}_{5}$ as Mo-precursor [35], the ALD window shown in Fig. $4 \mathrm{~b}$ is in the range of $155-175^{\circ} \mathrm{C}$. The surface reactions will also be incomplete at the temperature lower than the floor of the window. However, above the window, unlike $\mathrm{MoCl}_{5}$, the disordered stacks from the thermal decomposition of $\mathrm{Mo}(\mathrm{CO})_{6}$ bring an increase of GPC. While the other metal-organic $\mathrm{Mo}\left(\mathrm{NMe}_{2}\right)_{4}$ and $\mathrm{Mo}(\text { thd })_{3}$ are used as Moprecursors, ALD windows are $60-120$ and $275-325^{\circ} \mathrm{C}$, respectively $[38,46]$.

Compared with CVD, the lower temperature of ALD leads to the $\mathrm{MoS}_{2}$ film with a lower crystallinity. Moreover, while the metal-halide is used as the Moprecursor, the higher ALD window brings the higher crystallinity of $\mathrm{MoS}_{2}$. As described above, the ALD window depends on the activity of the precursor, and
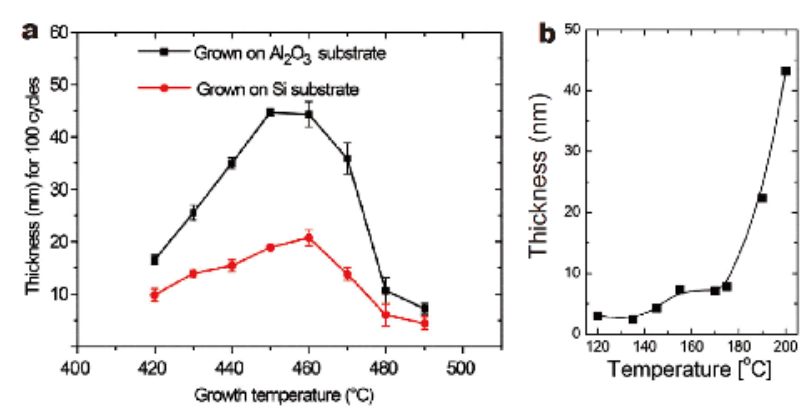

Figure 4 ALD temperature windows using different precursors. (a) $\mathrm{MoCl}_{5}$ and $\mathrm{H}_{2} \mathrm{~S}$. Reprinted with permission from Ref. [39], Copyright 2017, Elsevier. (b) $\mathrm{Mo}(\mathrm{CO})_{6}$ and $\mathrm{H}_{2} \mathrm{~S}$. Reprinted with permission from Ref. [35], Copyright 2014, Royal Society of Chemistry.

the $\mathrm{MoS}_{2}$ film with a high crystallinity needs to grow at a high temperature in the window.

\section{ALD substrates of $\mathrm{MoS}_{2}$}

As mentioned above, an ALD cycle contains two individual self-limiting surface reactions. Within the ALD window, it is necessary that a full coverage of monolayer can be realized by the precursor pulse, and the surface reactions will stop by themselves owing to the exhaustion of surface active sites, which endows ALD with a stable GPC and makes it insensitive to any further increase of the pulse length. By this stable GPC coming from the self-limiting reactions, the uniform and ultrathin $\mathrm{MoS}_{2}$ films can grow on the substrates even with complex structures, such as wires, powders, tubes, and holes/pores [25-27], which are the uniqueness of ALD. According to the crystallinity and orientation of the $\mathrm{MoS}_{2}$ films, not only the precursors but also the 
$\mathbf{a}$

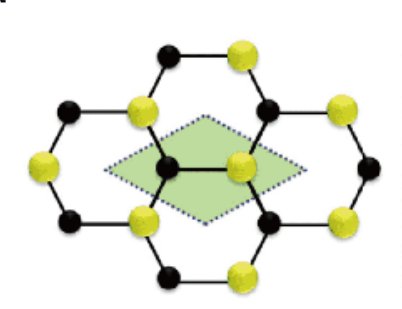

d

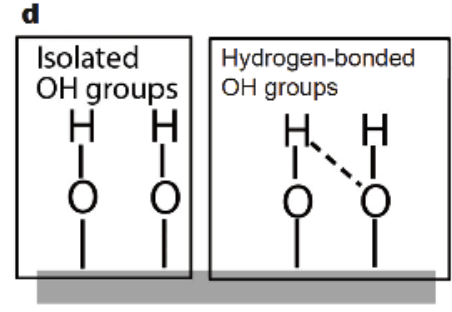

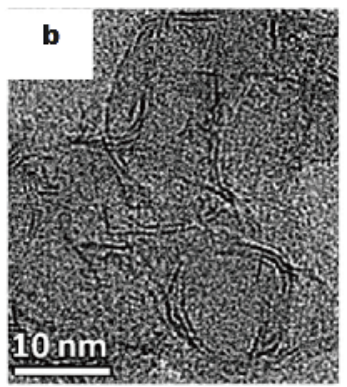

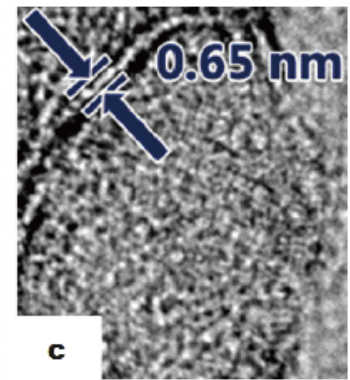

e

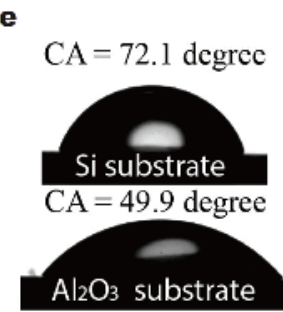

$f$

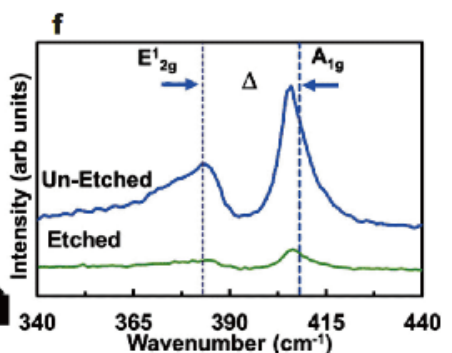

Figure 5 (a) A top view of $\mathrm{MoS}_{2}$. Reprinted with permission from Ref. [49], Copyright 2013, American Vacuum Society. (b) TEM image of MoS 2 by ALD on silica nano-bead. (c) $d_{0001}$ spacing. Reprinted with permission from Ref. [45], Copyright 2017, Royal Society of Chemistry. (d) Hydroxyl groups on the surface of the substrate. (e) Water contact angles of $\mathrm{Si}$ and $\mathrm{Al}_{2} \mathrm{O}_{3}$ substrates. Reprinted with permission from Ref. [39], Copyright 2017, Elsevier. (f) Raman spectra for ALD $\mathrm{MoS}_{2}$ films on etched and unetched substrate. Reprinted with permission from Ref. [33], Copyright 2016, American Vacuum Society.

substrates play an important role in ALD of $\mathrm{MoS}_{2}$.

On a sapphire substrate, the triangular grain with the size of $\sim 2 \mu \mathrm{m}$ can be obtained (by post-annealing) [29]. This may be attributed to the hexagonal crystal structure of the sapphire. The atomically smooth $(\mathrm{RMS}<0.1 \mathrm{~nm}) \mathrm{C}$ planes matches the (0001) planes of 2- $\mathrm{H} \mathrm{MoS}_{2}$ (Fig. 5a). This is propitious to the nucleation and growth of the large-size monocrystal $\mathrm{MoS}_{2}[49,50]$. When the $\mathrm{MoS}_{2}$ film is coated on a silica nano-bead surface [45], the (0001) planes of $\mathrm{MoS}_{2}$ perpendicular to the substrate can be observed (Fig. 5b, c). This structure can increase the number of active edge sites of the $\mathrm{MoS}_{2}$ films. In addition, the species and density of hydroxyl groups on the substrates are also very important to ALD of $\mathrm{MoS}_{2}$, especially for mono- or few-layer $\mathrm{MoS}_{2}$. In the initial stage of ALD, the $\mathrm{MoS}_{2}$ films are chemically adsorbed on the substrates through the hydroxyl groups. There are two different hydroxyl groups on the surface of substrates (Fig. 5d), hydrogen-bonded hydroxyl and isolated hydroxyl [51-53]. Above $200^{\circ} \mathrm{C}$, dehydroxylation will remove the hydrogen-bonded hydroxyl groups firstly. However, the isolated hydroxyl groups keep stable under $400^{\circ} \mathrm{C}$ [52]. Therefore, to obtain high quality $\mathrm{MoS}_{2}$ films, the interference of hydrogen-bonded hydroxyl should be excluded. A preheating process of the substrate at about $200^{\circ} \mathrm{C}$ before the growth is necessary. The acid washing and the oxygen plasma treatment can increase the density of hydroxyl groups on the surface of substrates. Moreover, the density can also be increased by covering the hydroxyl-rich seed layer on the substrates. The amorphous $\mathrm{Al}_{2} \mathrm{O}_{3}$ with abundant hydroxyl groups (Fig. 5e) is more suitable for ALD of $\mathrm{MoS}_{2}$ than the Si substrate [39]. The microcosmic surface structure of the substrates will also affect the crystallinity of the $\mathrm{MoS}_{2}$ films. According to the Raman spectra (Fig. 5f), the obtained $\mathrm{MoS}_{2}$ films on the etched $\mathrm{SiO}_{2}$ substrates have a higher crystallinity than those on the unetched substrates [33]. To obtain the high-quality $\mathrm{MoS}_{2}$ films, the crystal structure, surface functional groups and microcosmic structure of the substrate need to be considered.

\section{POST-ANNEALING OF $\mathrm{MoS}_{2}$ OBTAINED BY ALD}

Due to the low ALD window of $\mathrm{MoS}_{2}$, the as-deposited $\mathrm{MoS}_{2}$ films are commonly amorphous and/or nanocrystalline. To obtain the high crystallinity $\mathrm{MoS}_{2}$ film, post-annealing at the elevated temperature is usually necessary. In the post-annealing process, parameters such as the temperature, temperature-ramping speed, duration, and environment $\left(\mathrm{Ar}_{2}\right.$ and/or $\mathrm{S}_{2}$ atmosphere) should be considered. For the conventional semiconductor thin films [54,55], some changes usually in the heat treatments such as defects annihilation, stress build-up and release, morphological changes, and dopant activation may also 

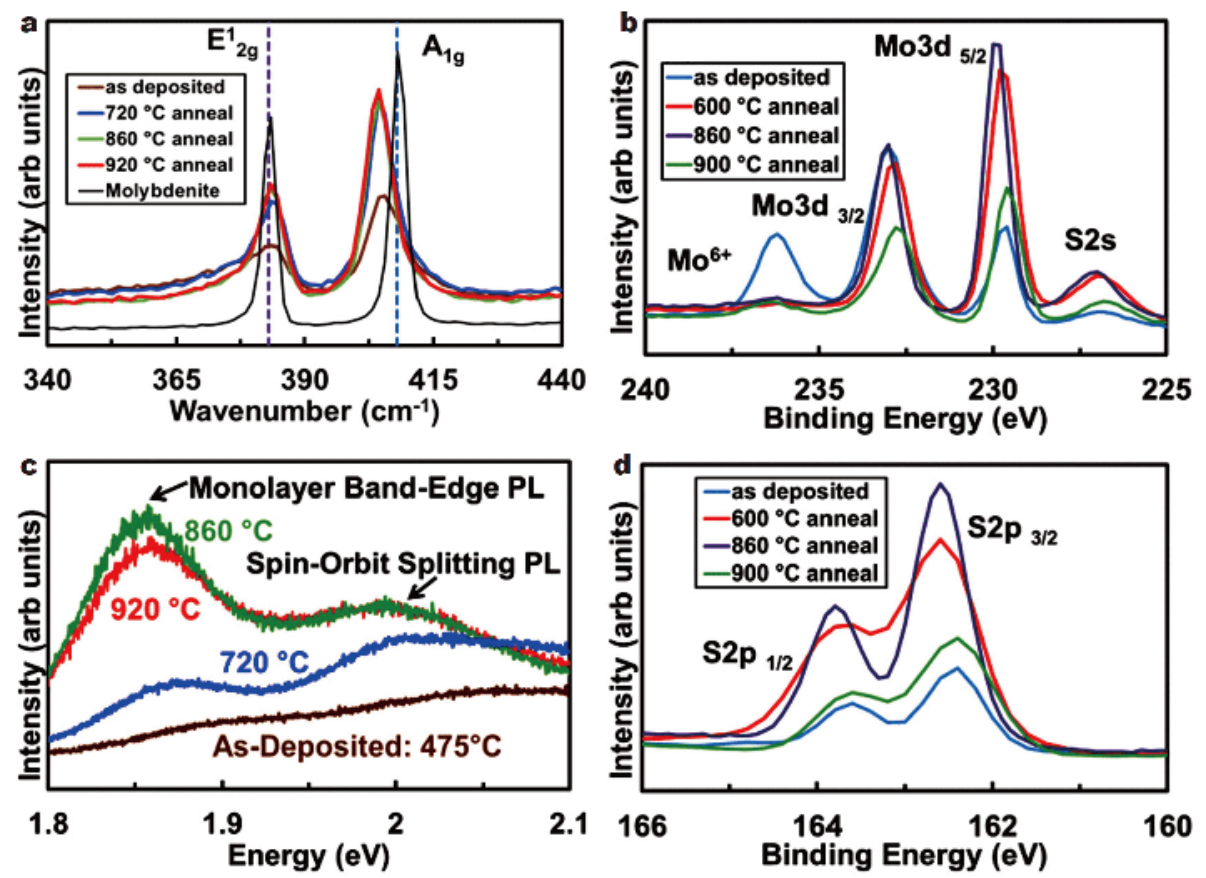

Figure 6 (a) Raman spectra of the as-deposited and sulfur-annealed $\mathrm{MoS}_{2}$ films. (b) Corresponding photoluminescence spectra. XPS spectra of Mo (c) and S (d). Reprinted with permission from Ref. [33], Copyright 2016, American Vacuum Society.

appear in the crystallization induced by post-annealing to the as-grown $\mathrm{MoS}_{2}$ films. Although the nano-crystalline $\mathrm{MoS}_{2}$ films can directly grow by ALD at $475^{\circ} \mathrm{C}$ using $\mathrm{MoCl}_{5}$ and $\mathrm{H}_{2} \mathrm{~S}$ as precursors, the crystallinity of the films can be improved by post-annealing in sulfur atmosphere [33]. Raman spectra of $\mathrm{MoS}_{2}$ films before and after annealing are shown in Fig. 6a, where the full width half maximum (FWHM) of $\mathrm{E}_{2 \mathrm{~g}}^{1}$ and $\mathrm{A}_{1 \mathrm{~g}}$ peaks is used to indicate the crystallinity. After post-annealing in sulfur atmosphere above $700^{\circ} \mathrm{C}$, the two peaks become strong and narrow, which indicates the high crystallinity of the as-grown $\mathrm{MoS}_{2}$ films. This can also be confirmed by the change of photoluminescence (PL) peaks before and after annealing (Fig. 6b). The X-ray photoelectron spectroscopy (XPS) of the as-grown and sulfur annealed $\mathrm{MoS}_{2}$ films are shown in Fig. $6 c$, d. The stoichiometric ratios of the films before and after post-annealing are determined by the intensity ratios of $S 2 p_{3 / 2}$ and Mo $3 d_{5 / 2}$ peaks. The increase of the $\mathrm{S} / \mathrm{Mo}$ ratio from 1.4 to 2.0 after annealing above $600^{\circ} \mathrm{C}$ suggests the improved substoichiometric sulfur ratio by high-temperature annealing in sulfur atmosphere.

The amorphous $\mathrm{MoS}_{2}$ (Fig. 7a) can be transformed into triangular $\mathrm{MoS}_{2}$ grains (Fig. 7b) with a size of $\sim 2 \mu \mathrm{m}$ on the sapphire after annealing at $800^{\circ} \mathrm{C}$ in sulfur ambient [29]. This is the largest monocrystalline $\mathrm{MoS}_{2}$ grown by
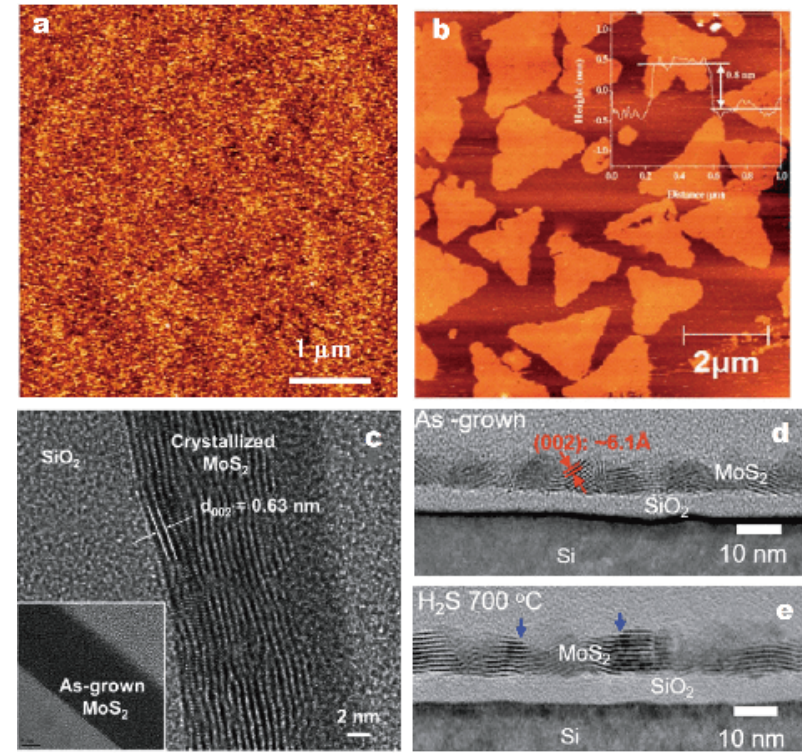

Figure 7 AFM images for as-grown (a) and annealed (b) $\mathrm{MoS}_{2}$ films on sapphire substrates. Reprinted with permission from Ref. [29], Copyright 2014, Royal Society of Chemistry. (c) Cross-sectional TEM images of the $\mathrm{MoS}_{2}$ film annealed at $900^{\circ} \mathrm{C}$. Reprinted with permission from Ref. [30], Copyright 2014, Royal Society of Chemistry. Cross-sectional TEM images of as-grown (d) and sulfurized (e) $\mathrm{MoS}_{2}$ on p-Si wafers at $700^{\circ} \mathrm{C}$. Reprinted with permission from Ref. [42], Copyright 2017, Royal Society of Chemistry. 
Table 2 Post-annealing processes of as-grown $\mathrm{MoS}_{2}$ films

\begin{tabular}{|c|c|c|c|c|c|c|c|c|}
\hline \multicolumn{4}{|c|}{ As-grown } & \multicolumn{5}{|c|}{ Post-annealing } \\
\hline Mo-precursor & S-precursor & S/Mo & Grain size & Temp. $\left({ }^{\circ} \mathrm{C}\right)$ & S/Mo & Grain size & Atmosphere & Ref. \\
\hline $\mathrm{MoCl}_{5}$ & $\mathrm{H}_{2} \mathrm{~S}$ & 1.97 & Amorphous & 800 & 2.03 & $20 \mu \mathrm{m}$ & S & [29] \\
\hline $\mathrm{Mo}(\mathrm{CO})_{6}$ & $\mathrm{CH}_{3} \mathrm{~S}_{2} \mathrm{CH}_{3}$ & 1.21 & Amorphous & 900 & 2.01 & Nano-crystalline & $\mathrm{Ar}$ & {$[30]$} \\
\hline $\mathrm{MoCl}_{5}$ & $\mathrm{H}_{2} \mathrm{~S}$ & 1.4 & Amorphous & $860-920$ & 2 & Nano-crystalline & $\mathrm{H}_{2} \mathrm{~S}, \mathrm{~S}$ & {$[33]$} \\
\hline $\mathrm{Mo}(\mathrm{CO})_{6}$ & $\mathrm{H}_{2} \mathrm{~S}$ & 1.5 & Amorphous & 900 & 2 & Nano-crystalline & $\mathrm{H}_{2} \mathrm{~S}, \mathrm{Ar}$ & {$[35]$} \\
\hline $\mathrm{Mo}\left(\mathrm{NMe}_{2}\right)_{4}$ & $\mathrm{H}_{2} \mathrm{~S}$ & I & Amorphous & 1,000 & l & $200 \mathrm{~nm}$ & S & {$[38]$} \\
\hline $\mathrm{Mo}(\mathrm{CO})_{6}$ & $\mathrm{H}_{2} \mathrm{~S}$ plasma & 1 & $6-10 \mathrm{~nm}$ & 600 & 2 & $14 \mathrm{~nm}$ & $\mathrm{H}_{2} \mathrm{~S}$ & {$[42]$} \\
\hline
\end{tabular}

ALD so far, which reveals the great potential of ALD in producing crystalline $\mathrm{MoS}_{2}$. Amorphous $\mathrm{MoS}_{2}$ has been obtained on the amorphous $\mathrm{Al}_{2} \mathrm{O}_{3}$ [38]. After annealing for $5 \mathrm{~h}$ at $1,000^{\circ} \mathrm{C}$ in sulfur ambient, the crystalline $\mathrm{MoS}_{2}$ film consisting of crystallites $(\sim 20 \mathrm{~nm})$ can be observed. The as-grown amorphous $\mathrm{MoS}_{2}$ also can be parallel to the $\mathrm{SiO}_{2}$ substrate (Fig. $7 \mathrm{c}$ ) after annealing for $5 \mathrm{~min}$ at $900^{\circ} \mathrm{C}$ in $\mathrm{Ar}$ ambient [30]. Cross-sectional TEM images of $\mathrm{MoS}_{2}$ grown at $200^{\circ} \mathrm{C}$ and annealed at $700^{\circ} \mathrm{C}$ on p-Si wafers [42] are shown in Fig. 7d, e. The grain sizes of the asgrown $\mathrm{MoS}_{2}$ are in the range of about $6-10 \mathrm{~nm}$ and the (002) plane spacing is about $6.1 \AA$. When the postannealing is carried out at $700^{\circ} \mathrm{C}$ in sulfur ambient, $\mathrm{MoS}_{2}$ grains grow to about $14 \mathrm{~nm}$ and the (002) plane of $\mathrm{MoS}_{2}$ will be in parallel to the Si substrate. These indicate the crystallinity is improved after post-annealing. The $\mathrm{MoS}_{2}$ obtained by post-annealing is the $2 \mathrm{H}$ phase. Thermodynamically, the $2 \mathrm{H}$ phase is more stable than $1 \mathrm{~T}$ and $1 \mathrm{~T}^{\prime}$ phases. They can be transformed into the $2 \mathrm{H}$ phase under heating. Post-annealing of the $\mathrm{MoS}_{2}$ films are shown in Table 2. The temperature above $600^{\circ} \mathrm{C}$ and the atmosphere such as $\mathrm{S}, \mathrm{H}_{2} \mathrm{~S}$, and $\mathrm{Ar}$ are generally used for annealing the as-grown $\mathrm{MoS}_{2}$. The crystallinity and substoichiometric sulfur of the as-grown $\mathrm{MoS}_{2}$ films can be improved by the high-temperature annealing. Because the ALD temperature of $\mathrm{MoS}_{2}$ is relatively low, postannealing is required to obtain the $\mathrm{MoS}_{2}$ films with a high crystallinity. Not only the crystallinity but also the substoichiometric sulfur of the $\mathrm{MoS}_{2}$ films can be improved by post-annealing.

\section{APPLICATIONS OF $\mathrm{MoS}_{2}$ OBTAINED BY ALD}

$\mathrm{Pt}$ is considered to be the most efficient catalyst for the electrochemical hydrogen evolution reaction (HER). However, Pt is insufficient and expensive. In fact, the HER activity is generally determined by the Gibbs free energy of hydrogen adsorption $\left(\Delta G_{\mathrm{H}^{*}}\right)$ [56,57]. Although
$\mathrm{MoS}_{2}$ as a HER catalyst has become a hot spot of research due to the small $\Delta G_{\mathrm{H}^{*}}$ on its edge sites [58], how to conveniently and economically increase the edge sites is still a problem for improving the HER activity [59-62]. Recently, amorphous or nanocrystal $\mathrm{MoS}_{2}$ obtained by ALD exhibits a high HER activity because they can enlarge the area of exposed edge sites [31,34,41,42].

HER polarization curves of a bare $\mathrm{Au}$ and two $\mathrm{MoS}_{2}$ films with different thickness obtained by ALD are shown in Fig. $8 \mathrm{a}$. When the current density reaches $100 \mu \mathrm{A} \mathrm{cm}{ }^{-2}$, the overpotential is designated as the onset potential. The onset potentials (165 and $181 \mathrm{mV}$ ) of thick and thin $\mathrm{MoS}_{2}$ films are much smaller than that of bare $\mathrm{Au}(222 \mathrm{mV})$, which indicates the $\mathrm{MoS}_{2}$ films have a better activity than the bare $\mathrm{Au}$ and the activity can be improved by increasing the thickness. HER polarization curves of the bare carbon fiber paper (CFP) and $\mathrm{MoS}_{2}$ films obtained by different ALD cycles are shown in Fig. 8b. For the $\mathrm{MoS}_{2} / \mathrm{Au}$ catalyst, the overpotential of $254 \mathrm{mV}$ is needed at the current density of $5 \mathrm{~mA} \mathrm{~cm}^{-2}$. However, at the same overpotential, the double current density can be obtained in the $\mathrm{MoS}_{2} / \mathrm{CFP}$ catalyst, which may be owing to the large active surface area. Tafel slope $b$ and exchange current density $j_{0}$ obtained from Fig. $8 \mathrm{a}$ and $\mathrm{b}$ are listed in Table 3. Although the $j_{0}$ of bare Au is about 1 order of magnitude bigger than that of $\mathrm{MoS}_{2}$ obtained by ALD, much smaller Tafel slope (47-50 $\mathrm{mV} \mathrm{dec}^{-1}$ ) of $\mathrm{MoS}_{2}$ than that $\left(88 \mathrm{mV} \mathrm{dec}^{-1}\right)$ of Au indicates $\mathrm{MoS}_{2}$ has a better HER activity than $\mathrm{Au}$ [62]. HER mechanism of ALD-MoS catalysts is the same because the Tafel slopes of ALD$\mathrm{MoS}_{2}$ catalysts are in a small range $\left(47-57 \mathrm{mV} \mathrm{dec}{ }^{-1}\right)$, and the main pathway for the HER may be the VH (VolmerHeyrovsky) [63].

Moreover, a type II heterojunction can be formed by coating $\mathrm{MoS}_{2}$ on $\mathrm{Si}$ [64-66]. In the $\mathrm{MoS}_{2} / \mathrm{Si}$ heterostructure, photoexcited electrons in Si will also participate in the HER by transporting to the $\mathrm{Si} / \mathrm{MoS}_{2}$ and $\mathrm{MoS}_{2} / \mathrm{H}_{2} \mathrm{O}$ interfaces. Nanocrystal $\mathrm{MoS}_{2}$ films grew on p-Si by ALD 

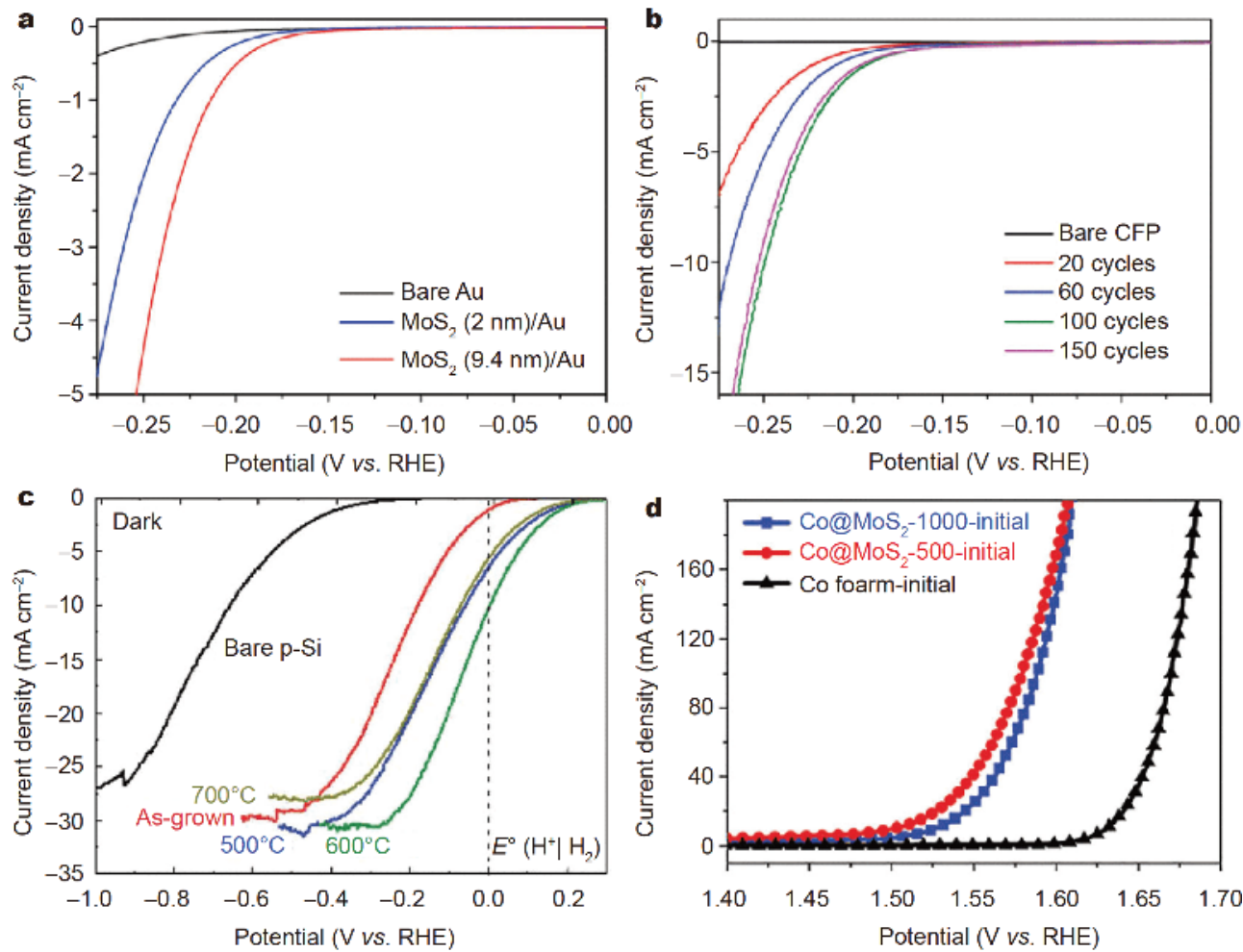

Figure 8 (a) HER polarization curves of bare $\mathrm{Au}$ and $\mathrm{MoS}_{2} / \mathrm{Au}$. Reprinted with permission from Ref. [31], Copyright 2015, American Chemical Society. (b) HER polarization curves of bare CFP and $\mathrm{MoS}_{2}$ /CFP. Reprinted with permission from Ref. [34], Copyright 2016, Royal Society of Chemistry. (c) PEC HER polarization curves of bare p-Si, as-grown and sulfurized $\mathrm{MoS}_{2} / \mathrm{p}$-Si. Reprinted with permission from Ref. [42], Copyright 2017, Royal Society of Chemistry. (d) OER polarization curves of bare Co foam and Co@MoS -500 grown by various cycles. Reprinted with permission from Ref. [43], Copyright 2017, Royal Society of Chemistry.

Table 3 Electrocatalytic activity of $\mathrm{MoS}_{2}$ obtained by ALD

\begin{tabular}{|c|c|c|c|c|}
\hline Sample & Tafel slope $\left(\mathrm{mV} \mathrm{dec}^{-1}\right)$ & $\left.J_{0}(\mu \mathrm{A} \mathrm{cm})^{-2}\right)$ & TOF at $0.2 \mathrm{~V} v s . \mathrm{RHE}\left(\mathrm{H}_{2} \mathrm{~s}^{-1}\right)$ & Ref. \\
\hline Bare Au & 88 & 0.293 & / & \multirow{4}{*}[31]{} \\
\hline $\mathrm{MoS}_{2}(2.0 \mathrm{~nm})$ & 50 & 0.024 & / & \\
\hline $\mathrm{MoS}_{2}(9.4 \mathrm{~nm})$ & 47 & 0.027 & 1.45 & \\
\hline Bare CFP & I & l & / & \\
\hline $\mathrm{MoS}_{2}(20$ cycles $)$ & 56.6 & 0.025 & $0.2-0.5$ & \multirow{4}{*}{ [34] } \\
\hline $\mathrm{MoS}_{2}(60$ cycles $)$ & 56.5 & 0.039 & $0.3-0.8$ & \\
\hline $\mathrm{MoS}_{2}$ (100 cycles) & 55.8 & 0.039 & $0.4-0.9$ & \\
\hline $\mathrm{MoS}_{2}$ (150 cycles) & 55.6 & 0.027 & $0.3-0.7$ & \\
\hline
\end{tabular}

using $\mathrm{Mo}(\mathrm{CO})_{6}$ and $\mathrm{H}_{2} \mathrm{~S}$ at $200^{\circ} \mathrm{C}$. Bare $\mathrm{p}$-Si, as-grown $\mathrm{MoS}_{2} / \mathrm{p}$-Si, and post-annealing $\mathrm{MoS}_{2} / \mathrm{p}$-Si were used for the photoelectrochemical (PEC) $\mathrm{H}_{2}$ [42]. Their PEC polarization curves are shown in Fig. 8c, where the overpotential of $\mathrm{MoS}_{2} / \mathrm{p}$-Si is much smaller than that of bare $\mathrm{p}$-Si at the same current density, indicating ALD$\mathrm{MoS}_{2}$ can obviously improve the PEC activity. ALD-MoS was also used as a catalyst for the $\mathrm{O}_{2}$ evolution reaction
(OER) $[43,67,68]$. The OER polarization curves of bare Co, Co@MoS -500 and $\mathrm{Co@MoS}_{2}-1000$ are shown in Fig. 8d, where the overpotential of $\mathrm{Co@MoS}$ is much smaller than that of bare Co at the same current density, indicating the ALD-MoS 2 has a better catalytic activity for OER. Moreover, the similar polarization curves of

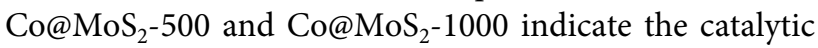
activity is insensitive to the thickness of $\mathrm{MoS}_{2}$. 
As described above, as an electrochemical catalyst, ALD-MoS $\mathrm{S}_{2}$ has the excellent catalytic activity both for HER and OER. The catalytic activity is insensitive to the number of cycles till it forms a continuous $\mathrm{MoS}_{2}$ film. However, the thickness of $\mathrm{MoS}_{2}$ has influence on the

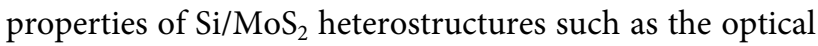
absorption, charge separation, and recombination, and thus affects the PEC activity. ALD- $\mathrm{MoS}_{2}$ with the amorphous structure has higher activity than that with the nanocrystal structure owing to the abundant active sites. Moreover, post-annealing can further improve the activity of $\mathrm{MoS}_{2}$, because annealing can make the grain perpendicular to the substrate and expose more active edges.

Therefore, there are two aspects needing to be paid attention to for improving the catalytic activity of ALD$\mathrm{MoS}_{2}$. The one is to make the $\mathrm{MoS}_{2}$ grain as small as possible and perpendicular to the substrate, thus exposing as many active sites as possible, which can be achieved by controlling the processes of the growth and postannealing. In order to obtain the $\mathrm{MoS}_{2}$ grain with a small size, ALD should be carried out by using the metalorganic compound with a high reactivity as the Moprecursor, and the substrate should avoid the plasma clean to keep the low surface energy. The $\mathrm{MoS}_{2}$ grain perpendicular to the substrate can be obtained by controlling post-annealing parameters such as the temperature, rates of heating and cooling. The other is to improve the conductivity of $\mathrm{MoS}_{2}$ through the doping of the conductive metal like $\mathrm{Cu}$ and $\mathrm{Ag}$. However, it is a challenge that keeping the small $\Delta G_{\mathrm{H}^{*}}$ of $\mathrm{MoS}_{2}$ edge unchangeable when the doping is introduced.

\section{CONCLUSION AND OUTLOOK}

In the ALD process, precursors, substrates, temperature and post-annealing treatments have influences on the quality of the $\mathrm{MoS}_{2}$ films. To directly and safely obtain high-quality $\mathrm{MoS}_{2}$ films by ALD, searching for novel precursors and optimizing process parameters are necessary. Metal-organic compound and metal-halide are used as Mo-precursors to deposit the $\mathrm{MoS}_{2}$ films. Metal-organic compound has a high reactivity while the obtained $\mathrm{MoS}_{2}$ films have a low crystallinity and GPC. Crystal structures, surface functional groups and microstructures of the substrates are also very important to ALD of $\mathrm{MoS}_{2}$. Hexagonal crystal substrates, acid pickling or plasma treating to increase the hydroxyl density of the substrate surface, annealing the substrate at $\sim 200^{\circ} \mathrm{C}$ to vanish the hydrogen-bonded hydroxyl groups may be useful for obtaining high crystalline $\mathrm{MoS}_{2}$ films by ALD.
Although the growth temperature is elevated to enlarge the size of the $\mathrm{MoS}_{2}$ grain obtained by ALD, the grain is still much smaller than that obtained by CVD. Therefore, in order to improve the crystalline quality, the postannealing is necessary.

Although the crystallinity of $\mathrm{MoS}_{2}$ obtained by ALD is lower than that obtained by CVD, the ALD- $\mathrm{MoS}_{2}$ film has shown excellent electrochemical properties as a catalysator in HER, OER, and PEC, which benefits from the abundant activity sites. The remaining challenge is how to improve the conductivity of ALD-MoS 2 and keep the small $\Delta G_{\mathrm{H}^{*}}$ unchangeable at the same time.

Adhesion and friction between contact surfaces seriously hinder the reliability and performance of the micro-electro-mechanical system (MEMS). In order to solve the problems, lubricant and protective films are usually coated on the surface of MEMS. Comparing with traditional technologies such as physical or chemical vapor deposition (PVD or CVD), ALD can easily deal with the challenge that how to conformally coat the film on the three-dimensional structure of MEMS. Therefore, as an excellent lubricating material, the $\mathrm{MoS}_{2}$ film obtained by ALD may provide the low friction surface required in MEMS.

\section{Received 11 December 2018; accepted 12 February 2019;} published online 4 March 2019

1 Radisavljevic B, Radenovic A, Brivio J, et al. Single-layer $\mathrm{MoS}_{2}$ transistors. Nat Nanotechnol, 2011, 6: 147-150

2 Ghatak S, Pal AN, Ghosh A. Nature of electronic states in atomically thin $\mathrm{MoS}_{2}$ field-effect transistors. ACS Nano, 2011, 5: 77077712

3 Baugher BWH, Churchill HOH, Yang Y, et al. Intrinsic electronic transport properties of high-quality monolayer and bilayer $\mathrm{MoS}_{2}$. Nano Lett, 2013, 13: 4212-4216

4 Wang F, Stepanov P, Gray M, et al. Annealing and transport studies of suspended molybdenum disulfide devices. Nanotechnology, 2015, 26: 105709

5 Wang F, Stepanov P, Gray M, et al. Ionic liquid gating of suspended $\mathrm{MoS}_{2}$ field effect transistor devices. Nano Lett, 2015, 15: 5284-5288

6 Wang QH, Kalantar-Zadeh K, Kis A, et al. Electronics and optoelectronics of two-dimensional transition metal dichalcogenides. Nat Nanotechnol, 2012, 7: 699-712

7 Bertrand PA. Surface-phonon dispersion of $\mathrm{MoS}_{2}$. Phys Rev B, 1991, 44: 5745-5749

8 Kam KK, Parkinson BA. Detailed photocurrent spectroscopy of the semiconducting group VIB transition metal dichalcogenides. J Phys Chem, 1982, 86: 463-467

9 Mak KF, Lee C, Hone J, et al. Atomically thin $\mathrm{MoS}_{2}$ : a new directgap semiconductor. Phys Rev Lett, 2010, 105: 136805

10 Wu S, Ross JS, Liu GB, et al. Electrical tuning of valley magnetic moment through symmetry control in bilayer $\mathrm{MoS}_{2}$. Nat Phys, 2013, 9: 149-153 
11 Mak KF, He K, Shan J, et al. Control of valley polarization in monolayer $\mathrm{MoS}_{2}$ by optical helicity. Nat Nanotechnol, 2012, 7: 494-498

12 Gurarslan A, Yu Y, Su L, et al. Surface-energy-assisted perfect transfer of centimeter-scale monolayer and few-layer $\mathrm{MoS}_{2}$ films onto arbitrary substrates. ACS Nano, 2014, 8: 11522-11528

13 Eda G, Yamaguchi H, Voiry D, et al. Photoluminescence from chemically exfoliated $\mathrm{MoS}_{2}$. Nano Lett, 2011, 11: 5111-5116

14 Wang X, Feng H, Wu Y, et al. Controlled synthesis of highly crystalline $\mathrm{MoS}_{2}$ flakes by chemical vapor deposition. J Am Chem Soc, 2013, 135: 5304-5307

15 Zhan Y, Liu Z, Najmaei S, et al. Large-area vapor-phase growth and characterization of $\mathrm{MoS}_{2}$ atomic layers on a $\mathrm{SiO}_{2}$ substrate. Small, 2012, 8: 966-971

16 Laskar MR, Ma L, Kannappan S, et al. Large area single crystal (0001) oriented $\mathrm{MoS}_{2}$. Appl Phys Lett, 2013, 102: 252108

17 Tarasov A, Campbell PM, Tsai MY, et al. Highly uniform trilayer molybdenum disulfide for wafer-scale device fabrication. Adv Funct Mater, 2014, 24: 6389-6400

18 Shi J, Ma D, Han GF, et al. Controllable growth and transfer of monolayer $\mathrm{MoS}_{2}$ on Au foils and its potential application in hydrogen evolution reaction. ACS Nano, 2014, 8: 10196-10204

19 Lee YH, Zhang XQ, Zhang W, et al. Synthesis of large-area $\mathrm{MoS}_{2}$ atomic layers with chemical vapor deposition. Adv Mater, 2012, 24: 2320-2325

20 Yang S, Kang J, Yue Q, et al. Vapor phase growth and imaging stacking order of bilayer molybdenum disulfide. J Phys Chem C, 2014, 118: 9203-9208

21 van der Zande AM, Huang PY, Chenet DA, et al. Grains and grain boundaries in highly crystalline monolayer molybdenum disulphide. Nat Mater, 2013, 12: 554-561

22 Zhang J, Yu H, Chen W, et al. Scalable growth of high-quality polycrystalline $\mathrm{MoS}_{2}$ monolayers on $\mathrm{SiO}_{2}$ with tunable grain sizes. ACS Nano, 2014, 8: 6024-6030

23 Kong L, Wang Q, Xiong S, et al. Turning low-cost filter papers to highly efficient membranes for oil/water separation by atomiclayer-deposition-enabled hydrophobization. Ind Eng Chem Res, 2014, 53: 16516-16522

24 Zhou Y, King DM, Li J, et al. Synthesis of photoactive magnetic nanoparticles with atomic layer deposition. Ind Eng Chem Res, 2010, 49: 6964-6971

25 Miikkulainen V, Leskelä M, Ritala M, et al. Crystallinity of inorganic films grown by atomic layer deposition: overview and general trends. J Appl Phys, 2013, 113: 021301

26 Leskelä M, Ritala M, Nilsen O. Novel materials by atomic layer deposition and molecular layer deposition. MRS Bull, 2011, 36: 877-884

27 George SM. Atomic layer deposition: an overview. Chem Rev, 2010, 110: 111-131

28 Leskelä M, Ritala M. Atomic layer deposition chemistry: recent developments and future challenges. Angew Chem Int Ed, 2003, 42: 5548-5554

29 Tan LK, Liu B, Teng JH, et al. Atomic layer deposition of a $\mathrm{MoS}_{2}$ film. Nanoscale, 2014, 6: 10584-10588

30 Jin Z, Shin S, Kwon DH, et al. Novel chemical route for atomic layer deposition of $\mathrm{MoS}_{2}$ thin film on $\mathrm{SiO}_{2} / \mathrm{Si}$ substrate. Nanoscale, 2014, 6: 14453-14458

31 Shin S, Jin Z, Kwon DH, et al. High turnover frequency of hydrogen evolution reaction on amorphous $\mathrm{MoS}_{2}$ thin film directly grown by atomic layer deposition. Langmuir, 2015, 31: 1196-1202
32 Browning R, Padigi P, Solanki R, et al. Atomic layer deposition of $\mathrm{MoS}_{2}$ thin films. Mater Res Express, 2015, 2: 035006

33 Valdivia A, Tweet DJ, Conley Jr. JF. Atomic layer deposition of two dimensional $\mathrm{MoS}_{2}$ on $150 \mathrm{~mm}$ substrates. J Vacuum Sci Tech AVacuum Surfs Films, 2016, 34: 021515

34 Kwon DH, Jin Z, Shin S, et al. A comprehensive study on atomic layer deposition of molybdenum sulfide for electrochemical hydrogen evolution. Nanoscale, 2016, 8: 7180-7188

35 Pyeon JJ, Kim SH, Jeong DS, et al. Wafer-scale growth of $\mathrm{MoS}_{2}$ thin films by atomic layer deposition. Nanoscale, 2016, 8: 1079210798

36 Liu L, Huang Y, Sha J, et al. Layer-controlled precise fabrication of ultrathin $\mathrm{MoS}_{2}$ films by atomic layer deposition. Nanotechnology, 2017, 28: 195605

37 Jang Y, Yeo S, Lee HBR, et al. Wafer-scale, conformal and direct growth of $\mathrm{MoS}_{2}$ thin films by atomic layer deposition. Appl Surf Sci, 2016, 365: 160-165

38 Jurca T, Moody MJ, Henning A, et al. Low-temperature atomic layer deposition of $\mathrm{MoS}_{2}$ films. Angew Chem Int Ed, 2017, 56: 4991-4995

39 Huang Y, Liu L, Zhao W, et al. Preparation and characterization of molybdenum disulfide films obtained by one-step atomic layer deposition method. Thin Solid Films, 2017, 624: 101-105

40 Huang Y, Liu L, Sha J, et al. Size-dependent piezoelectricity of molybdenum disulfide $\left(\mathrm{MoS}_{2}\right)$ films obtained by atomic layer deposition (ALD). Appl Phys Lett, 2017, 111: 063902

41 Ho TA, Bae C, Lee S, et al. Edge-on $\mathrm{MoS}_{2}$ thin films by atomic layer deposition for understanding the interplay between the active area and hydrogen evolution reaction. Chem Mater, 2017, 29: 7604-7614

42 Oh S, Kim JB, Song JT, et al. Atomic layer deposited molybdenum disulfide on $\mathrm{Si}$ photocathodes for highly efficient photoelectrochemical water reduction reaction. J Mater Chem A, 2017, 5: 3304-3310

43 Xiong D, Zhang Q, Li W, et al. Atomic-layer-deposited ultrafine $\mathrm{MoS}_{2}$ nanocrystals on cobalt foam for efficient and stable electrochemical oxygen evolution. Nanoscale, 2017, 9: 2711-2717

44 Zhang T, Wang Y, Xu J, et al. High performance few-layer $\mathrm{MoS}_{2}$ transistor arrays with wafer level homogeneity integrated by atomic layer deposition. 2D Mater, 2018, 5: 015028

45 Cadot $\mathrm{S}$, Renault $\mathrm{O}$, Frégnaux M, et al. A novel 2-step ALD route to ultra-thin $\mathrm{MoS}_{2}$ films on $\mathrm{SiO}_{2}$ through a surface organometallic intermediate. Nanoscale, 2017, 9: 538-546

46 Mattinen M, Hatanpää T, Sarnet T, et al. Atomic layer deposition of crystalline $\mathrm{MoS}_{2}$ thin films: new molybdenum precursor for lowtemperature film growth. Adv Mater Interfaces, 2017, 4: 1700123

47 Mane AU, Letourneau S, Mandia DJ, et al. Atomic layer deposition of molybdenum disulfide films using $\mathrm{MoF}_{6}$ and $\mathrm{H}_{2} \mathrm{~S}$. J Vacuum Sci Tech A-Vacuum Surfs Films, 2018, 36: 01A125

48 Liu H. Recent progress in atomic layer deposition of multifunctional oxides and two-dimensional transition metal dichalcogenides. J Mol Eng Mater, 2016, 04: 1640010

49 Xu M, Liang T, Shi M, et al. Graphene-like two-dimensional materials. Chem Rev, 2013, 113: 3766-3798

50 Huang $\mathrm{H}, \mathrm{Li} \mathrm{X}, \mathrm{Xu} \mathrm{X}$. An experimental research on the force and energy during the sapphire sawing using reciprocating electroplated diamond wire saw. J Manuf Sci Eng, 2017, 139: 121011

51 Mathieu MV, Primet M, Pichat P. Infrared study of the surface of titanium dioxides. II. Acidic and basic properties. J Phys Chem, 1971, 75: 1221-1226 
52 Primet M, Pichat P, Mathieu MV. Infrared study of the surface of titanium dioxides. I. Hydroxyl groups. J Phys Chem, 1971, 75: 1216-1220

53 Bezrodna T, Puchkovska G, Shymanovska V, et al. IR-analysis of H-bonded $\mathrm{H}_{2} \mathrm{O}$ on the pure $\mathrm{TiO}_{2}$ surface. J Mol Struct, 2004, 700: 175-181

54 Liu H, Chi D. Magnetron-sputter deposition of $\mathrm{Fe}_{3} \mathrm{~S}_{4}$ thin films and their conversion into pyrite $\left(\mathrm{FeS}_{2}\right)$ by thermal sulfurization for photovoltaic applications. J Vacuum Sci Tech A-Vacuum Surfs Films, 2012, 30: 04D102

55 Li ZQ, Chen H, Liu HF, et al. Influence of Si doping on optical characteristics of cubic GaN grown on (001) GaAs substrates. Appl Phys Lett, 2000, 76: 3765-3767

56 Conway BE, Bockris JOM. Electrolytic hydrogen evolution kinetics and its relation to the electronic and adsorptive properties of the metal. J Chem Phys, 1957, 26: 532-541

57 Nørskov JK, Bligaard T, Rossmeisl J, et al. Towards the computational design of solid catalysts. Nat Chem, 2009, 1: 37-46

58 Hinnemann B, Moses PG, Bonde J, et al. Biomimetic hydrogen evolution: $\mathrm{MoS}_{2}$ nanoparticles as catalyst for hydrogen evolution. J Am Chem Soc, 2005, 127: 5308-5309

59 Jaramillo TF, Jørgensen KP, Bonde J, et al. Identification of active edge sites for electrochemical $\mathrm{H}_{2}$ evolution from $\mathrm{MoS}_{2}$ nanocatalysts. Science, 2007, 317: 100-102

60 Karunadasa HI, Montalvo E, Sun Y, et al. A molecular $\mathrm{MoS}_{2}$ edge site mimic for catalytic hydrogen generation. Science, 2012, 335: 698-702

61 Kibsgaard J, Jaramillo TF, Besenbacher F. Building an appropriate active-site motif into a hydrogen-evolution catalyst with thiomolybdate $\left[\mathrm{Mo}_{3} \mathrm{~S}_{13}\right]^{2-}$ clusters. Nat Chem, 2014, 6: 248-253

62 Conway BE, Tilak BV. Interfacial processes involving electrocatalytic evolution and oxidation of $\mathrm{H}_{2}$, and the role of chemisorbed H. Electrochim Acta, 2002, 47: 3571-3594

63 Li Y, Wang H, Xie L, et al. $\mathrm{MoS}_{2}$ nanoparticles grown on graphene: an advanced catalyst for the hydrogen evolution reaction. J Am Chem Soc, 2011, 133: 7296-7299

64 Tsai ML, Su SH, Chang JK, et al. Monolayer $\mathrm{MoS}_{2}$ heterojunction solar cells. ACS Nano, 2014, 8: 8317-8322

65 Merki D, Fierro S, Vrubel H, et al. Amorphous molybdenum sulfide films as catalysts for electrochemical hydrogen production in water. Chem Sci, 2011, 2: 1262-1267

66 Kwon KC, Choi S, Hong K, et al. Wafer-scale transferable molybdenum disulfide thin-film catalysts for photoelectrochemical hydrogen production. Energy Environ Sci, 2016, 9: 2240-2248

67 McCrory CCL, Jung S, Ferrer IM, et al. Benchmarking hydrogen evolving reaction and oxygen evolving reaction electrocatalysts for solar water splitting devices. J Am Chem Soc, 2015, 137: 4347-4357

68 Wang J, Cui W, Liu Q, et al. Recent progress in cobalt-based heterogeneous catalysts for electrochemical water splitting. Adv Mater, 2016, 28: 215-230

Acknowledgements This work is financially supported by the National Natural Science Foundation of China (51822501), the Natural Science Funds for Distinguished Young Scholar of Jiangsu Province (BK20170023), the Fundamental Research Funds for the Central Universities (3202006301 and 3202006403), Qing Lan Project of Jiangsu Province, the International Foundation for Science, Stockholm, Sweden, the Organization for the Prohibition of Chemical Weapons, the Hague, Netherlands, through a grant to Lei Liu (F/4736-2), the grants from Top 6 High-Level Talents Program of Jiangsu Province (2017-GDZB-006, Class A), the Natural Science Foundation of Jiangsu Province (BK20181274), the Scientific Research Foundation of Graduate School of Southeast University (YBPY1703), the Open Research Fund of Jiangsu Key Laboratory for Design and Manufacture of Micro-Nano Biomedical Instruments, Southeast University (KF201806), the Scientific Research Fund of Nanjing Institute of Technology (YKJ201859), the Tribology Science Fund of State Key Laboratory of Tribology (SKLTKF15A11), Open Research Fund of State Key Laboratory of High Performance Complex Manufacturing, Central South University (Kfkt2016-11), Open Research Fund of State Key Laboratory of Fire Science (HZ2017-KF05) and Open Research Fund of State Key Laboratory of Solid Lubrication (LSL-1607).

Author contributions Liu L proposed the topic and outline of the manuscript. Huang Y collected the related information and wrote the manuscript.

Conflict of interest The authors declare no conflict of interest. 


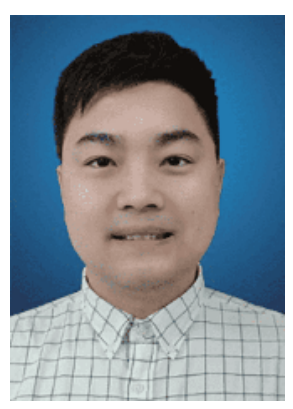

Yazhou Huang received his $\mathrm{PhD}$ degree from the School of Mechanical Engineering at Southeast University of China in 2018. He joined Nanjing Institute of Technology as a lecturer in 2018. His research interest is mainly focused on the synthesis of nanomaterials for electronic device applications.

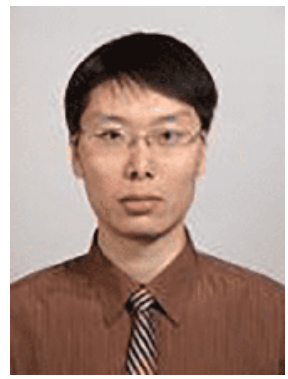

Lei Liu is a Professor of the School of Mechanical Engineering at Southeast University. He is a Distinguished Young Scholar of the National Science Foundation of Jiangsu Province, Excellent Young Scholar of the National Science Foundation of China. He received his PhD degree from the University of Science and Technology of China in 2007. His current research interest focuses on the nanomaterials and devices for medical detection.

\section{原子层沉积二硫化锄的研究进展}

黄亚洲 ${ }^{1,2}$, 刘磊 ${ }^{2 *}$

摘要 作为一种特殊的化学气相沉积技术, 原子层沉积在薄膜制造领域得到广泛的应用. 得益于自限制化学反应, 原子层沉积所制备的薄 膜具有优异的均匀性且精确可控. 基于原子层沉积技术, 在复杂、大面积基底上制备的薄膜厚度可以控制在原子尺度精度 $(0.1 \mathrm{~nm})$. 因此, 它已经被用来制备二维 $\mathrm{MoS}_{2}$ 材料. 本综述首先介绍了原子层沉积 $\mathrm{MoS}_{2}$ 薄膜的相关研究进展, 然后就前驱体、衬底、温度和退火等工艺参 数对薄膜质量的影响进行了分析, 最后对原子层沉积制备的 $\mathrm{MoS}_{2}$ 在电化学催化领域的应用进行了评论. 该综述不仅回顾了原子层沉积 $\mathrm{MoS}_{2}$ 的研究进展, 而且指出了尚存的挑战和突破的希望. 